\section{Revista Brasileira de Administração Científica}

Brazilian Journal of Scientific Administration

Abr a Jun 2021 - v.12 - n.2
ISSN: 2179-684X

\title{
Políticas públicas socioeducacionais: implantação do ensino integral na rede pública em Cacoal - Rondônia
}

\begin{abstract}
A presente pesquisa foi realizada em duas escolas estaduais, localizada no município de Cacoal no estado de Rondônia (Uma atende o Projeto Guaporé e a outra o Projeto Escola do Novo Tempo e a Escola da Escolha). Metodologicamente foram adotados métodos mistos análise dos resultados, para obtenção de dados foi aplicado questionários com questões referentes à determinação estipulada pelo Plano Nacional de Educação - PNE, mais especificamente a Meta de Número 06 tendo como objetivo obter os dados necessários para análise de indicadores que proporcionem interpretar o cenário de implantação do Ensino Integral no município, e visionar a viabilidade da determinação em relação ao aumento da carga horária, serão verificados através dos dados obtidos a veracidade do aumento da carga horária de 04 (Quatro) para 07 (Sete) horas como estipula a Meta número 06 do Plano Nacional de Educação - PNE de acordo com a Lei 13.005 , de 25 de junho de 2014, juntamente com a práxis metodológica utilizada pelas respectivas escolas e o impacto que a mudança trouxe no decorrer do projeto. O resultado proporcionou averiguar que a implantação do tempo escolar pensada para mitigar a ausência de justiça social a comunidades mais carentes, tem como lacuna a própria aceitação dos estudantes, levando o quadro de funcionários a exercerem o constante papel de motivador para manter e conquistar novos alunos. Os professores por meio da metodologia de projetos buscam estratégia para sanar as dificuldades de aprendizagem, bem como utilizar as orientações pedagógicas do programa do ICE que apresenta o projeto de vida, o nivelamento e uma formação integral como práxis metodológica para atender a Meta 06 da PNE. A ausência de ampliação de infraestrutura é um dos fatores agravantes que inviabilizam em totalidade as Estratégias propostas pela Meta 06.
\end{abstract}

Palavras-chave: Políticas Públicas Socioeducacionais; Educação Integral; Ampliação do tempo Escolar.

\section{Socio-educational public policies: implementation of integral education in the public system in Cacoal - Rondônia}

\begin{abstract}
The present research was carried out in two state schools, located in the municipality of Cacoal in the state of Rondônia (one school serves the 'Guaporé' Project and the other serves the 'School of the New Time' and the 'School of Choice' Projects). Mixed methods of analysis of the results were adopted. Questionnaires were applied to obtain data containing questions referring to the determination stipulated by the National Education Plan - PNE, more specifically the Sixth Goal, aiming to obtain the necessary data for the analysis of indicators that provide understand of the scenario for the implementation of Integral Education in the municipality and envisage the feasibility of the determination about the increase in the number of hours. The veracity of the increase in the number of hours from 04 (four) to 07 (seven) hours will be verified as specifies the Sixth Goal of the National Education Plan (NEP) according to Law 13,005 of 25th June of 2014 , with the methodological praxis used by the respective schools and the impact that the change brought during the project. The result enabled us to ascertain that the implementation of school time designed to mitigate the absence of social justice in the neediest communities has as a gap the students' acceptance, leading the staff to exercise the constant role of motivator to keep and conquer new students' trust. Teachers through the methodology of projects seek a strategy to remedy learning difficulties, using the pedagogical guidelines of the Co-responsibility for Education Institute (CEI) program that presents the life project, leveling and an integral training as methodological praxis to meet the Sixth Goal of the NEP. The absence of infrastructure expansion is one of the aggravating factors that render the Strategies proposed by the Sixth Goal unfeasible.
\end{abstract}

Keywords: Socio-educational Public Policies; Integral Education; Extension of school time.

Topic: Gestão Pública

Reviewed anonymously in the process of blind peer.
Received: 04/04/2021

Approved: 06/06/2021
Elaine Cristina Rodrigues Prado (i)

Faculdade de Pimenta Bueno, Brasil

http://lattes.cnpq.br/7583313740344103

http://orcid.org/0000-0001-8085-9218

kris prado br@hotmail.com

Claudia Cleomar Araujo Ximenes Cerqueira (iD

Universidade Federal de Rondônia, Brasil

http://lattes.cnpq.br/8014015246571237

http://orcid.org/0000-0002-4125-7991

profa.ximenescerqueira@gmail.com

Nubia Deborah Araujo Caramello id

Universidade Federal de Rondônia, Brasil

http://lattes.cnpq.br/8155132371455051

http://orcid.org/0000-0002-2167-9759

geocaramellofrj@gmail.com

\section{Referencing this:}

PRADO, E. C. R.; CERQUeIRA, C. C. A. X.; CARAMELlO, N. D. A.. Políticas públicas socioeducacionais: implantação do ensino integral na rede pública em Cacoal - Rondônia. Revista Brasileira de Administração Científica, v.12, n.2, p.179-197, 2021. DOI:

http://doi.org/10.6008/CBPC2179-684X.2021.002.0015 


\section{INTRODUÇÃO}

O Governo brasileiro através de políticas públicas para eficiência do setor educacional tem discutindo a possibilidade de uma Educação Integral nas escolas de todo o país. O que veio se tornar meta decisiva no contexto educacional no estado de Rondônia, inicialmente com o Projeto Mais Educação implantado com o nome de Projeto Guaporé, ofertado ao ensino fundamental e médio (CARVALHO et al., 2019), e em 2014, com o Plano Nacional de Educação (PNE), por meio da Lei 13.005, de 25 de junho de 2014 - Com vigência por 10 (dez) anos, pode ampliar a proposta implantando no ano de 2017 as 11 (onze) escolas de tempo integral no Estado através do projeto intitulado Escola da Escolha destinada aos alunos do ensino médio. Trilhando a meta proposta pela Lei que objetiva que 50\% das escolas públicas implantem até 2024 o ensino em tempo integral em todo o país.

E sobre esse panorama que a instituição escolar passar a receber das políticas públicas das esferas estaduais e municipais um protagonismo de ser a esfera onde as justiças sociais possam ser alcançadas, levando a um conhecimento integral (CARVALHO, 2006; ESTÊVÃO, 2016). Um desafio que que se implanta junto ao desejo de uma educação pública de qualidade, é a ausência de suporte físico, financeiro e humano como relatado por vários pesquisadores que debruçaram sobre a temática (BRANCO, 2012; BRAGANÇA et al., 2016), desafios esses que recaem sobre o gestor público educacional.

As escolas de tempo integral estão no cenário do município de Cacoal, Rondônia, onde acontece os dois projetos pilotos do Governo supracitados anteriormente. Ainda que o objetivo é ampliar o tempo do aluno na escola as metodologias da gestão do tempo e da intervenção pedagógicas se diferem nas duas escolas, localizadas na zona urbana do município. Embora a 'ordem' seja vertical, o contexto da pesquisa é construído a partir do olhar sobre o espaço local, onde, de fato as coisas acontecem.

A densidade demográfica é superior a 20,7 habitantes por $\mathrm{km}^{2}$, sendo uma das cidades mais povoada do Estado. A renda média dos habitantes é 2 salários mínimos. Contudo importante salientar que de acordo com o último censo $22,2 \%$ da população encontrava-se empregada formalmente é $35,6 \%$ da população recebiam menos de $1 / 2$ salário mínimo, tendo a bolsa família uma grande contribuição a esse valor. Cenário territorial que justifica a relevância da implantação de uma educação em tempo integral no espaço escolar, oportunizando oportunidades de formação integral. As políticas de combate às desigualdades apostavam na educação integral como estratégia para ampliar o acesso a alimentação, formação integral e diversificada. 0 Plano Nacional de Educação (PNE), especificamente, a Meta Número 6, norteia todo este estudo. Determinante que aja adesão de escolas estaduais e municipais, para a implementação da escola em tempo integral, Cacoal, participa com duas escolas, uma no centro e a outra na periferia. Motivação que levou as pesquisadoras do presente estudo a analisarem ambas realidades alimentadas pelas propostas governamentais que buscam políticas socioeducacionais e sua real aplicabilidade.

Alicerçando sobre esses contextos o objetivo dessa pesquisa buscou descrever as práxis metodológicas utilizadas no município de Cacoal em relação à Educação Integral, comparar o processo de ensino vivenciado com o Plano Nacional de Educação (PNE), especificamente em relação a Meta número 06, 
identificar e descrever o preparo das escolas quanto às questões pedagógicas para oferecer o serviço educativo segundo a determinação do PNE. Um olhar que se alimentou das percepções dos atores envolvidos sobre os desafios e expectativas, tornando as vozes dos profissionais da educação o principal núcleo de análise do conteúdo da informação.

\section{METODOLOGIA}

\section{Área de estudo e amostra da pesquisa}

Fazem parte do estudo às escolas da rede pública do estado de Rondônia localizadas no município de Cacoal, sendo elas a Escola Estadual de Ensino Médio em Tempo Integral Josino Brito (EEEMTI - Josino Brito) e a Escola Estadual de Ensino Fundamental e Médio Carlos Drummond de Andrade (EEEFM - Carlos Drummond de Andrade) selecionadas por terem em comum a implantação da ampliação do tempo escolar, designado por projetos específicos. Dois projetos se destacam: o Guaporé inserido no ano de 2013 e o Escola do Novo Tempo implantada em meados de 2017.

Juntas as escolas tem uma população de 186 profissionais (todas as funções). Deste foram autoselecionados como amostra da pesquisa 30 profissionais que voluntariamente se propuseram a responder o questionário. Destes obteve-se o retorno de 22 , o que equivale uma amostra de $12 \%$ da população da escola e $73 \%$ população amostral pretendida.

\section{Coleta de dados e unidade de análise}

A obtenção de dados quantitativo e qualitativo nos aproxima de uma visão mais ampla da identidade territorial das escolas em análise. Para o INEP "Os indicadores educacionais atribuem valor estatístico à qualidade do ensino", atendo-se não somente ao desempenho dos alunos, mas também a percepção da equipe escolar e o contexto econômico e social em que as escolas estão inseridas.

Visando analisar realidades que somente podem ser compreendidas a partir da experiência vivenciada pelos autores que nela estão inseridos, em se tratando de duas realidades distintas em um cenário de rede pública, a pesquisa será o "estudo de caso" que "[...] se caracteriza como um tipo de pesquisa cujo objeto é uma unidade que se analisa profundamente. Visa ao exame detalhado de um ambiente, de um simples sujeito ou de uma situação em particular". Portanto, é uma pesquisa do tipo qualitativo. Os dados qualitativos também podem ser analisados por meio de uma estatística descritiva por meio de categorias de analises como propõem Bardin (2011).

O desafio de analisar a subjetividade está presente nesta metodologia, porém também oportuniza identificar dois cenários a partir de quem está inserido neles. O desenho de um questionário de entrevistas possui as questões abertas e fechadas sendo um eficiente instrumento de coletas de dados como explicam Silveira et al. (2009). Para ampliar a eficiência os procedimentos de aplicação dos questionários foram seguidos as seguintes estratégias: (1) Questionário aplicado aos professores, técnicos e direção escolar com questões abertas, semiestruturadas e fechadas. (2) esperou-se pelo retorno de todos os questionários. (3) 
foram entregues o questionário durante uma semana, levando em conta que os profissionais da educação que atuam nas escolas podem não se encontrarem todos no mesmo dia na escola, e (4) na intenção de obter o maior número de questionários foram entregues 45 formulários, sendo estipulado mais de um dia para ser entregue os questionários diretamente a pesquisadora que o aplicou. De forma que as dúvidas pudessem ser sanadas.

A partir do banco de dados criados (todas entrevistas foram digitadas em planilhas Excel para visão global das respostas), inicia uma sequência de ações que vão da estadística descritiva a análise das respostas e refinamento das que serão empregadas na categorização, interpretação das mesmas envolve a redução dos dados, a sua categorização, sua interpretação e a redação do relatório (BARDIN, 2011; PRODANOV et al., 2013).

\section{RESULTADO E DISCUSSÃO}

\section{Perfil das Escolas e dos entrevistados}

A escola Estadual de Ensino Fundamental e Médio Carlos Drummond de Andrade (Fig. 1), está inserida entre as escolas que atuam com a modalidade de tempo integral, ofertada aos alunos de $6^{\circ}$ ano do Ensino Fundamental II ao $3^{\circ}$ do Ensino Médio, por meio do Projeto Guaporé, de iniciativa estadual que ampliou a jornada escolar, tendo início no ano de 2013, através da Resolução № 1074/12-CEE/RO, de 05 de novembro de 2012 e publicado no diário oficial do Estado de Rondônia № 2121 de 18 de dezembro de 2012 (CARVALHO et al., 2019).

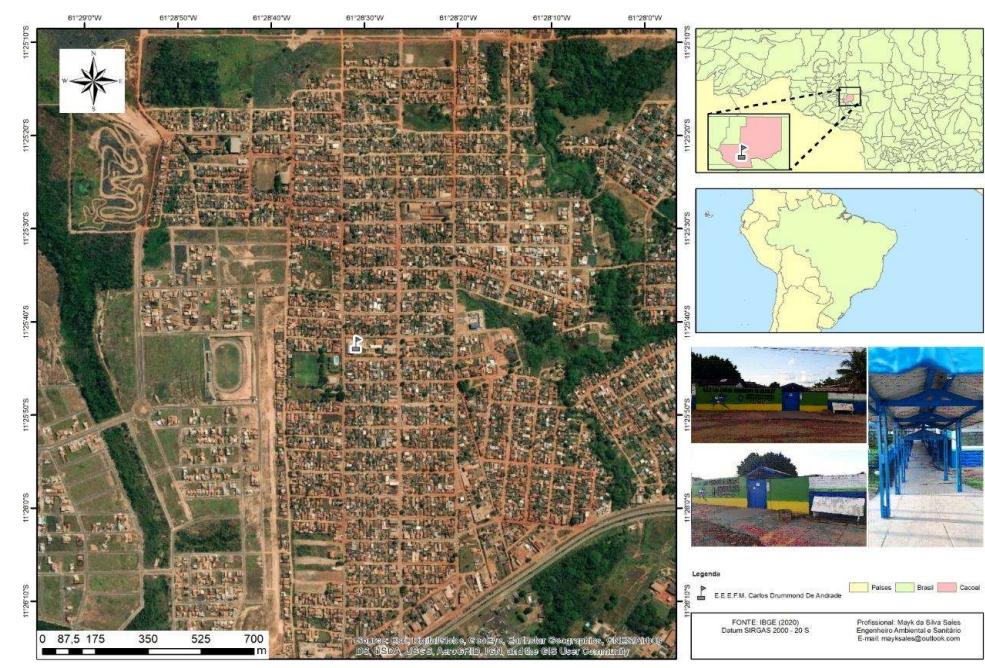

Figura 1: Localização da EEEFM Carlos Drummond de Andrade.

Localizado no bairro Vista Alegre, a escola conta com 14 salas de aula, oferece aula nos três turnos, sendo que no período noturno somente há aulas para o ensino médio. No ano de 2017, havia 21 turmas matriculadas, tendo uma média de 23 a 30 alunos por sala. Tendo também uma sala para o Atendimento Educacional Especializado, que em 2017 atendia 11 estudantes $^{1}$. Na observação realizada sobre o ambiente

${ }^{1}$ EEEFM - Escola Estadual de Ensino Fundamental e Médio (Escola Pública Estadual), 2017. https://www.escol.as/1325-carlos-drummond-de-andrade 
da escola, constatou-se que a Escola é grande, porém a estética necessita de algumas reformas. As salas de aulas são climatizadas, além destas possui: salas de diretoria, supervisão e orientação, sala dos professores de boa qualidade. Conta com um laboratório de informática e um de ciências que estão em situação regular devido à falta de manutenção nos equipamentos; a biblioteca e de boa qualidade falta mais estrutura para se tornar atrativa.

A cozinha é boa e agrupada a um pequeno refeitório apertado, fator que leva a maioria dos alunos almoçarem e lancharem no pátio coberto, porém em pé ou sentados no chão, pois as mesas que tem são poucas. Os banheiros que os alunos utilizam são regulares, pois não tem banheiros suficientes considerando que a jornada diária leva muitos alunos precisarem tomar banho e fazer uso mais constante desse ambiente,

A escola não possui psicólogo, tem somente psicopedagogo que atende na sala de Atendimento Educacional Especializado - AEE. O abastecimento de água e energia é de ótima qualidade de acordo com os gestores. Considerando que Rondônia é um estado com clima equatorial. A ausência de áreas verde amplia a sensação térmica dos ambientes externos, um agravante pois, observou-se que a área verde é bem escassa no ambiente escolar tendo apenas dois espaços com jardim, e alguns vasos com plantas penduradas e espalhadas pelo pátio. Em contrapartida a quadra escolar é grande e coberta.

A escola conta com uma equipe de professores dedicados que criaram umas práxis metodológica a partir de experiência já adquirida com projetos de ampliação de jornada escolar. Para atender a normativa da Meta 06 do PNE, que solicita a implantação de escolas em tempo integral, em todo o país, se organiza duas práxis metodológicas facilmente identificáveis, a primeira corresponde a organização do horário escolar: as disciplinas curriculares são oferecidas em um turno e no contra turno é desenvolvido oficinas de acompanhamento.

O horário inicia as 7:00 e encerra as 17:30 horas, oferecendo o tempo de permanência dos estudantes na escola de aproximadamente 10 horas diárias. 0 descanso que ocorre na própria escola sobre a responsabilidade da gestão escolar tem duração de 2:00 horas. Para que o tempo de permanência na escola seja voltado à busca da qualidade da aprendizagem. A segunda práxis metodológicas, corresponde à ementa criada pelos professores para ofertarem no contra turno um currículo alternativo atrativo e que contemple também os reforços para diminuir as defasagens de aprendizagem.

No contra turno são oferecidas aulas de Língua Portuguesa e Matemática, Artesanato (origami), Educação Ambiental - Sala Verde, Cultura - dança, Educação para paz, Esporte e lazer- judô e memórias e histórias da comunidade. Para atender essa dinâmica do currículo alternativo é realizado uma escala para realização das atividades por parte dos profissionais que atuam na escola.

A Escola Estadual de Ensino em Tempo Integral Josino Brito está localizada, no Bairro Floresta (Fig. 2), estruturado também com 14 salas de aula distribuída em média de 31 a 38 alunos por sala. Tendo como clientela somente alunos do Ensino Médio ao todo são 12 turmas, atendidos no período matutino e vespertino. Como a EEEFM Carlos Drummond de Andrade também oferta o Atendimento Educacional 
Especializado².

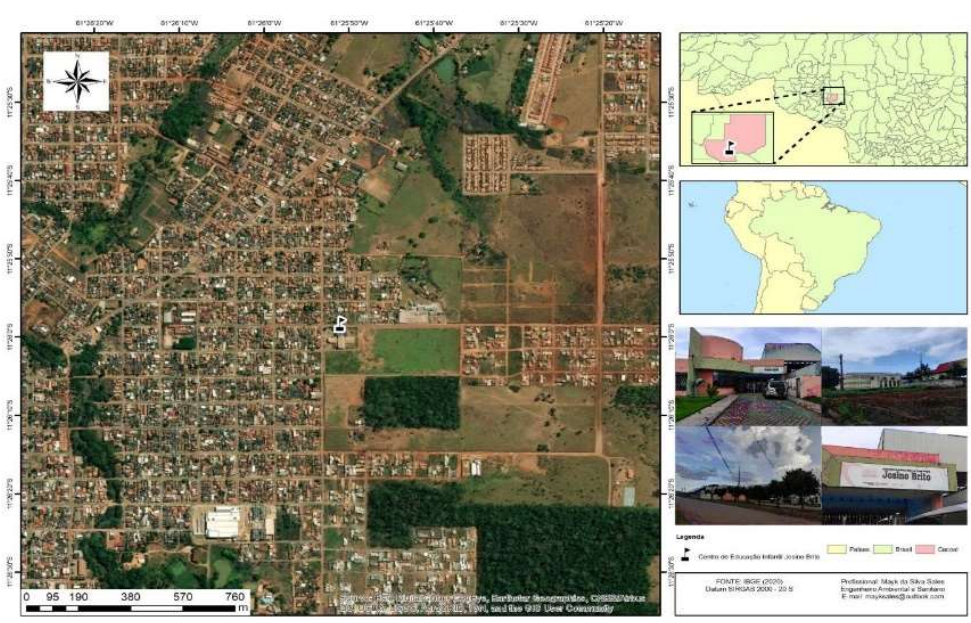

Figura 2: Localização da EEETI Josino Brito.

Na observação realizada do ambiente da escola, identificou-se que tem uma estética agradável. Sendo aparentemente bem estruturada com salas de aulas espaçosas e climatizada, possui salas de diretoria, e coordenação pedagógica (supervisão e orientação). Apresenta sala dos professores, laboratório de informática e um de ciências e biblioteca similar a escola anterior citada. Possui um auditório amplo onde os alunos utilizam para apresentações de teatro e também usam no momento de descanso do almoço que tem a duração de 1 hora e 20 minutos.

Um dos problemas é a cozinha é muito apertada, também não possui refeitório onde todos os alunos possam juntos almoçar e lanchar, de forma que grande parte deles optam em realizar as refeições no pátio coberto, porém estando em pé ou sentados no chão, pois as mesas que tem no refeitório são insuficientes. Também é no pátio que fazem Educação Física já que a escola não possuía quadra. Os banheiros que os alunos utilizam são regulares, já os dos funcionários é somente um. Apesar de um amplo espaço a área verde é bem escassa tendo apenas dois espaços pequenos, com um jardim, mas bem organizado.

A escola conta com uma equipe de professores com dedicação exclusiva. A práxis metodológica segue uma proposta curricular sugerida pelo Instituto de Corresponsabilidade pela Educação - ICE, levando a oferta de aulas de pensamentos científico, estudo orientado, guia de aprendizagem, disciplinas eletivas, ênfases nas práticas experimentais aulas de projeto de vida e preparação para o Enem. A organização do horário diferente da escola Carlos Drummond de Andrade, não se dividem em turnos para as disciplinas consideradas tradicionais ou que constam na Base Nacional Comum Curricular. O horário busca um equilíbrio com o currículo ampliado. As disciplinas optativas são elaboradas pelos professores, criando ementa, metodologia e geralmente são elaboradas para atender os sonhos de vida dos alunos, sendo como o próprio nome diz optativa a escolha de qual gostaria de se matricular, não podendo o estudante não optar por nenhuma (REIS et al., 2017).

Passou a desenvolver a proposta de Ensino em Tempo Integral a partir do ano letivo de 2017, através do Programa Federal 'Escola da Escolha' adaptado pelo Projeto Estadual 'Escola do Novo Tempo', em

${ }^{2}$ EEEFM - Escola Estadual de Ensino Fundamental e Médio (Escola Pública Estadual), 2017. https://www.escol.as/2324-josino-brito 
cooperação estabelecida entre a Secretaria de Educação do Estado de Rondônia - ICE e membros cooperativos como o Instituto Sonho Grande e o Instituto Natura. Fato que justifica o porquê de ter um menor número de profissionais trabalhando, em comparação a EEEFM Carlos Drummond de Andrade que também atende um maior de alunos (Fig. 3).

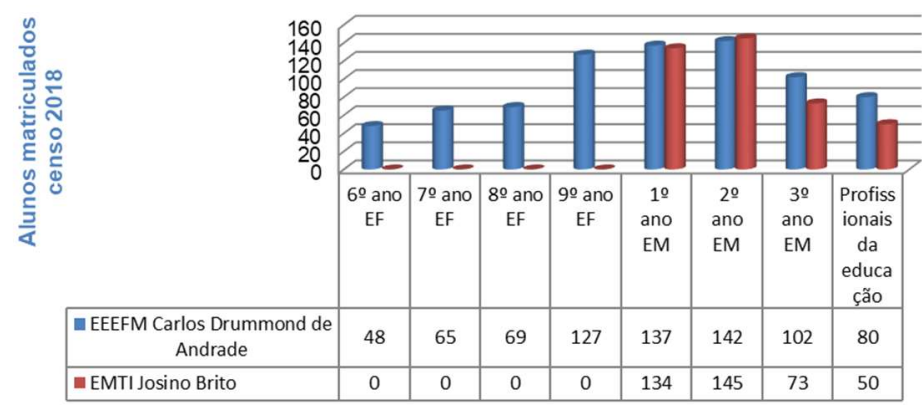

Figura 3: Alunos Matriculados - Censo de 2018. Fonte: Organizado pelas autoras a partir de dados disponibilizados na plataforma ${ }^{3}$.

A primeira escola tem a ação de ampliação de jornada escolar oriunda da iniciativa do Programa Mais Educação, criado pela Portaria Normativa Interministerial № 17 em 24 de abril de 2007, tendo vigência até 2016, período que encerra a ajuda financeira do Governo Federal. Já a segunda escola é projetada no Programa Novo Mais Educação regido inicialmente pela Portaria N 1.144 de 10 de outubro de 2016. Ambos os projetos fazem parte de iniciativa do Governo Federal. A referida Portaria ainda que substituída pela Resolução FNDE n 17/2017, traz em sua base de origem a Lei de Diretrizes e Base da Educação (LDB) e a implantação das Metas 6 e 7, lançadas em 2014 pelo Plano Nacional de Educação (PNE) de acordo com a Lei 13.005, de 25 de junho de 2014.

Que o inciso I do art. 32 da Lei de Diretrizes e Bases da Educação Nacional - LDB, Lei no 9.394, de 20 de dezembro de 1996, determina o desenvolvimento da capacidade de aprender, tendo como meios básicos o pleno domínio da leitura, da escrita e do cálculo; Que o art. 34 da LDB, Lei no 9.394, de 1996, determina a progressiva ampliação do período de permanência na escola; Que a família, a comunidade, a sociedade e o poder público devem assegurar, com absoluta prioridade, a efetivação dos direitos referentes à vida, à saúde, à alimentação, à educação, ao esporte, ao lazer, à profissionalização, à cultura, à dignidade, ao respeito, à liberdade e à convivência familiar e comunitária, nos termos do. (BRASIL, 2016)

Os resultados do IDEB, foram indicadores quantitativos utilizados pelos gestores para propor uma nova dinâmica no ensino público com foco nos domínios da leitura e da escrita, objetivo norteadores muito claros tanto no Programa Mais Educação como no Programa Novo Mais Educação. Todavia, para atender a Meta 6 do PNE e propor uma educação integral a alunos estudante em tempo integral, foi necessário estabelecer outras parcerias e ampliar a área curricular da contemplação do ensino, neste âmbito entra o papel do ICE na EEEMTI Josino Brito, não sendo relatado ou encontrado resposta se o ICE também atenderia a EEMTI Carlos Drummond de Andrade. Um outro ator essencial é o gestor público que tem o papel de motivador de toda a equipe escolar para o alcance da qualidade do ensino público e tornar eficaz as políticas públicas (PEREIRA, 2020). Ainda para o supracitado autor somente uma gestão democrática e participativa

\footnotetext{
${ }^{3}$ Banco de dados EMTI Josino de Brito, disponível em: https://www.qedu.org. br/escola/244286-eeem-josino-brito/sobre. - Banco de dados da EEFM Carlos Drummond de Andrade. Disponível em: https://www.qedu.org.br/escola/243055-eeefm-carlos-drummond-de-andrade/censo-escolar 
proporcionará tal conquista.

\section{Os Entrevistados: vozes da experiência do espaço trabalhado}

De forma harmônica, porém não intencional $64 \%$ dos entrevistados que retornaram os questionários de ambas as escolas são do sexo feminino, seguindo uma tendência de predominância nacional que tem menos de $30 \%$ do gênero masculino na profissão, de acordo com o censo professores de $2007^{4}$. Seis modalidades de profissionais da educação (Fig. 4) responderam o questionário. Destes predominaram os que exercem a função de docentes com $68 \%$ de participação, sendo que a os da EMTI Josino Brito predominou a categoria em $91 \%$ dos questionários recebidos.

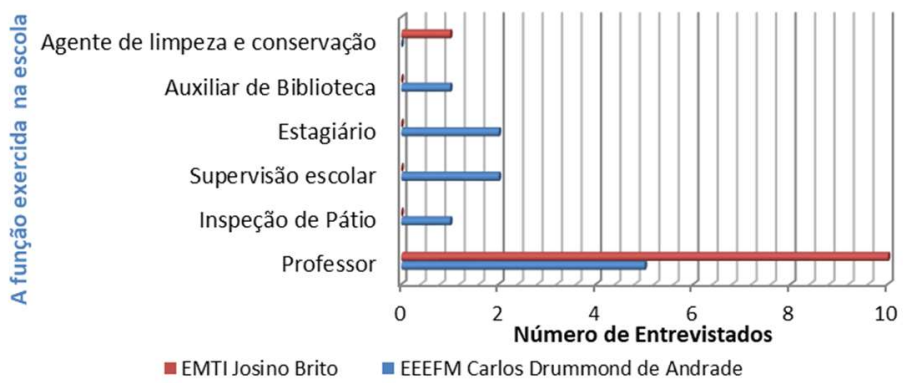

Figura 4: A Função exercida pelos profissionais entrevistado.

Importante observar que a EEEFM Carlos Drummond apresentou a maior diversidade de função exercida na escola entre os entrevistados, ainda que predomina entre as funções a de professores representando $45 \%$ dos entrevistados. O nível de instrução dos entrevistados predominou em $68 \%$ os que possuem Lato Sensu e apenas $5 \%$ dos entrevistados tinha o nível médio como maior titulação (Fig. 5), esse fator evidencia que o nível de formação dos profissionais de ambas a instituição independente da função exercida corresponde à formação esperada no século XXI.

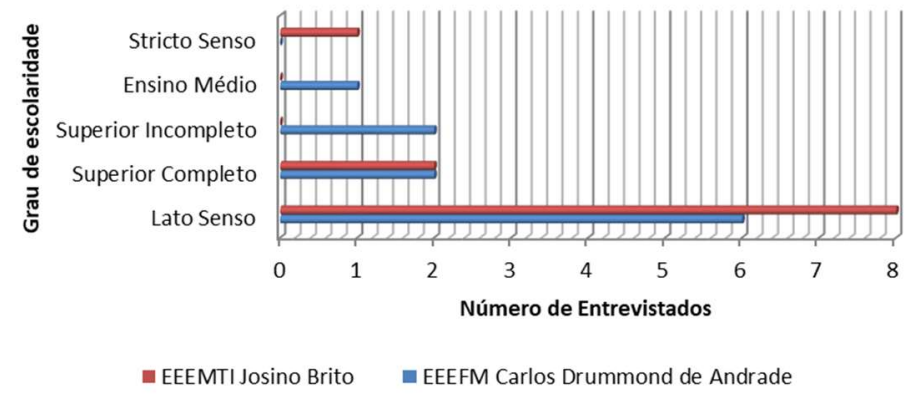

Figura 5: Número de Entrevistados.

Outro indicador que o gráfico evidencia é a formação contínua dos profissionais que ao agregarmos o Stricto Sensu somam $69 \%$ dos profissionais que não se contentaram apenas com a graduação, buscando ampliar seu conhecimento. O número não é maior em razão de faltar incentivo para seguirem os estudos nesta modalidade. $\mathrm{O}$ envolvimento desses profissionais em algum tipo de conselho, como por exemplo: equipe diretiva; Conselho Municipal de Educação, entre outros é maior na EEEFM Carlos Drummond de

${ }^{4}$ Censo 2007. Disponível em: http://portal.mec.gov.br/plano-nacional-de-formacao-de-professores/censo-do-professor 
Andrade com $82 \%$ dos entrevistados integrantes e no EMTI Josino Brito $73 \%$. Um percentual considerado elevado de envolvimento para as duas escolas.

\section{Conhecimento sobre: proposta Político Pedagógico (PPP); o Regimento Escolar e sobre a organização do trabalho escolar}

Ao serem questionados sobre a relação do Projeto Pedagógico - PP e do Regimento da Escola, com a prática em sala de aula, a análise global identificou que 68\% informaram serem importantes, e 73\% afirmaram que leva em consideração essas normativas internas na elaboração de seus planos de aula. 0 índice de participação na elaboração do PP e no Regimento Interno da escola foi muito similar nas duas escolas o que possibilita uma análise global, identificando que $59 \%$ dos entrevistados contribuíram com a construção desse importante documento, considerado como o coração da escola. Porém $27 \%$ alegaram não terem contribuído e $14 \%$ optaram em não responder.

Entre o emprego das normativas internas no planejamento e a participação da construção do documento, pode-se identificar, que o percentual que não a considera no planejamento é muito próximo dos quais os que não participaram de sua elaboração, somando com os que optaram em não responder. Fator que podem evidenciar que a ausência do sentimento de fazer parte da construção do documento pode levar ao distanciamento de seu uso. Um fator que precisa ser observado quando se almeja o alinhamento para alcançar o objetivo da Meta $\mathrm{O} 6$ do PNE, podendo comprometer todas as Estratégias em especial a 6.9 que visa 'adotar medidas para otimizar o tempo de permanência dos alunos na escola, direcionando a expansão da jornada para o efetivo trabalho escolar, combinado com atividades recreativas, esportivas e culturais'. O tempo em uma escola de educação integral é um fator que precisa ser bem amarrado na proposta curricular com a PPP, para que possa se convertido de fato em instrumento para busca da qualidade no ensino.

Quadro 1: De onde partem para elaboração de seu trabalho na escola.

\begin{tabular}{|c|c|c|}
\hline & EEEFM Carlos Drummond de Andrade & EMTI Josino Brito \\
\hline 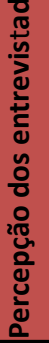 & $\begin{array}{l}\text { Projeto de vida dos estudantes e das diretrizes nacionais e } \\
\text { regionais (estado). } \\
\text { Competências da escola. } \\
\text { Quadro de profissionais. } \\
\text { Visão e filosofia da escola } \\
\text { Projeto de vida, PCN's, BNCC e referência curricular do estado. } \\
\text { Projeto de vida e diferencial curricular de RO, diretrizes da } \\
\text { educação nacional. } \\
\text { Na coordenação. }\end{array}$ & $\begin{array}{l}\text { Nas Legislações vigentes } \\
\text { O PPP elaborado pela equipe gestora, professores e } \\
\text { alunos. } \\
\text { Proposta Curricular, PPP, Regimento Interno, } \\
\text { planejamento anterior. } \\
\text { Baseado no livro adotado e no plano do governo. }\end{array}$ \\
\hline
\end{tabular}

Ainda que identificado essa lacuna a partir das respostas, observa-se que há outras normativas sendo seguidas, como as referências de escala nacional e/ou regional. Também observamos que as propostas pelo projeto onde as escolas estão inseridas moldam às práxis metodológica da organização do planejamento escolar, regido não somente pela proposta de conteúdo mais também o currículo como um todo. Traços também identificados pela proposta chave do ICE que traz o projeto de vida como um fator que precisa ser seguido na busca da escola da escolha. A categoria 'Projeto de Vida' esteve mais presente na EEEFM Carlos Drummond de Andrade, enquanto que a preocupação com o 'Projeto Pedagógico', foi categoria 
predominante na EEEMTI Josino Brito, no momento de planejamento das ações desenvolvidas pelos entrevistados, como pode ser analisado no quadro 1.

O fato de que a EEEFM Carlos Drummond de Andrade iniciou o projeto em 2013, tendo já uma identidade com a proposta de tempo integral, pode ser o fator da incorporação da filosofia do Programa, enquanto que a EMTI Josino Brito teve iniciou na expansão do tempo escolar no ano de 2017. Ao serem questionados se o PP e o Regimento Escolar contemplam a Educação Integral, os profissionais da EEEFM Carlos Drummond de Andrade 91\% sim e 9\% não. Contudo profissionais da EMTI Josino Brito 27\% sim, 9\% e $64 \%$ optaram em não se manifestar. Sendo justificados por distintas razões como pode ser observado no quadro 2

Quadro 2: Percepções sobre o porquê o Regimento Escolar não contempla a Educação Integral.

\begin{tabular}{|c|c|c|}
\hline "ू & EEEFM Carlos Drummond de Andrade & EMTI Josino Brito \\
\hline 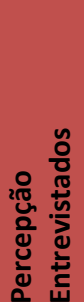 & $\begin{array}{l}\text { Foi feito dentro da proposta Crítica Social dos Conteúdos. } \\
\text { Estabelece regras e normas para serem cumpridas. } \\
\text { Todos os projetos desenvolvidos precisam estar registrados no PP } \\
\text { para serem desenvolvido. } \\
\text { Por que tem assunto relativo sobre a Educação Integral. } \\
\text { De forma a desenvolver a diversidade cultural e habilidades no que } \\
\text { diz respeito a aquisição de conhecimentos, no entanto deixa a } \\
\text { desejar. }\end{array}$ & $\begin{array}{l}\text { Está em reelaboração. } \\
\text { Somente no ano de } 2019 \text {. } \\
\text { O modelo da escola integral trabalha com PPP e } \\
\text { regimento escolar da escola regular. } \\
\text { Ainda não foi construído o PP e Regimento para } \\
\text { a escola integral. }\end{array}$ \\
\hline
\end{tabular}

Os professores do Projeto Guaporé e do Projeto Escola do Novo Tempo afirmam terem participado de cursos para se compreender o projeto ao menos uma vez. Um outro fator que precisa ser considerado é o tempo de experiência inserido na proposta de ampliação do tempo escolar, um processo de adaptação que leva tempo tanto para o aluno quanto para os docentes. Fica claro quando identificamos que a EEEFM Carlos Drummond de Andrade tem no quadro de profissionais entrevistas pelo menos $45 \%$ que alegaram já ter experiência com o Projeto Mais Educação, enquanto que a EMTI Josino Brito havia 27\%.

Quadro 3: Percepções sobre a formação continuada.

\begin{tabular}{|l|l|}
\hline \multicolumn{2}{l}{ EEEFM Carlos Drummond de } \\
Andrade
\end{tabular}

A formação continuada oferecida pela própria escola é uma característica na EEEMTI Josino Brito, na qual $100 \%$ dos entrevistados registraram participar desses momentos. Vale evidenciar que a proposta do ICE no Projeto Escola da Escolha é que semanalmente ocorram momentos pedagógicos para o alinhamento das práxis pedagógicas. Um dos critérios para ser inserido no programa Escola do Novo Tempo implantado no EEEMTI Josino Brito é o comprometimento de dedicação exclusiva à escola devendo os profissionais estar 
40 horas semanais a disposição da agenda pedagógica da escola, fator que pode evidenciar o alto índice de participação. No EEEFM Carlos Drummond, o índice é de 55\%, o fato de os profissionais que responderam o questionário pertencerem a funções diferenciadas pode explicar esse percentual. Sobre os benefícios desses momentos os entrevistados das supracitadas escolas apresentam concordância que o processo de formação traz grande relevância para a reflexão pedagógica (Quadro 3).

Na defesa da implantação do programa na escola, evidenciado o porquê ela seria a ideal, as respostas se organizam em torno das categorias analíticas: Competência Docente - Necessidade discente Infraestrutura ampliada, sobre a última também há um apelo que esta categoria ainda que tenha sido feita algumas adaptações, elas são insuficientes (Quadro 4).

Quadro 4: Percepções sobre os favoráveis na escola para receber a Educação Integral.

\begin{tabular}{|c|c|c|}
\hline & EEEFM Carlos Drummond de Andrade & EMTI Josino Brito \\
\hline & $\begin{array}{l}\text { O quadro de professores. } \\
\text { O corpo docente, a formação oferecida pelos parceiros, mas quanto } \\
\text { a estrutura física da escola ainda falta muitas coisas: refeitório, } \\
\text { ampliação dos banheiros, área para realização das atividades dos } \\
\text { clubes. } \\
\text { Estrutura, apesar de precisar de muitas melhorias para contemplar } \\
\text { todas as necessidades, corpo docentes preparados para a demanda. } \\
\text { Os estudantes e a estrutura da escola, além do corpo docente. } \\
\text { A equipe escolar, corpo docente qualificando. } \\
\text { Espaço. } \\
\text { A equipe escolar } \\
\text { O modelo privilegia o projeto de vida do estudante. Exerce a } \\
\text { pedagogia da presença com os educandos. Procura o sucesso e a } \\
\text { manutenção do estudante na escola. } \\
\text { Melhor formação da cidade. } \\
\text { Quadro de profissionais. }\end{array}$ & $\begin{array}{l}\text { As oficinas ajudam os alunos nos reforços } \\
\text { escolares. } \\
\text { Tem tempo distinto para se planejar o aluno na } \\
\text { escola. } \\
\text { A vontade de trabalhar, porque não há } \\
\text { infraestrutura. Atende as necessidades da } \\
\text { comunidade periférica, no caso também } \\
\text { econômica. } \\
\text { Melhor infraestrutura. } \\
\text { Alunos melhores preparados nos resultados do IDB } \\
\text { e SAERO Deveria contemplar com a prática de } \\
\text { oficinas que de fato favoreça o cognitivo. } \\
\text { Professores Competentes. } \\
\text { Infraestrutura de qualidade, biblioteca acessível. } \\
\text { A organização do tempo, sendo as manhãs usadas } \\
\text { para as disciplinas e a tarde para atividades do } \\
\text { projeto. } \\
\text { A necessidade dos alunos e da comunidade. }\end{array}$ \\
\hline
\end{tabular}

Observa-se pelos relatos que há uma defesa em prol da implantação da escola em tempo integral, com a valorização da equipe, com a metodologia que vem sendo implantada mediada pelo projeto de vida dos discentes e o reconhecimento que a proposta pode suprir a carência dos alunos e da comunidade. Esses elementos indicam uma empatia pela Meta 06 proposta pelo PNE. Como também fortifica o protagonismo da escola na implantação das políticas públicas socioeducacionais.

\section{Concepção dos professores sobre a interação dos alunos}

Ainda que a empatia seja um marco relevante para implantação de uma proposta metodológica de ensino, ela precisa também estar presente no público a qual se destina. Uma conquista que não é espontânea e precisa fazer sentido, melhor seria se pudesse ser uma alternativa, que não é o que ocorre nas escolas analisadas. Vista como uma oportunidade para os pais que acreditam que os filhos 'estarão bem' nas escolas em tempo integral, cabe a eles a decisão de onde os filhos irão estudar. Até que a dinâmica diária seja internalizada pelos alunos, a participação será um grande desafio, como identificado (Quadro 5).

Quadro 5: Percepção dos docentes quanto à participação dos discentes. 
Abraçam a causa, porém desejam algo novo, que os motive a estar ali participando.

Os alunos ficam cansados pois, falta área de descanso. Participação do próprio aluno.

Participam uma média de $10 \%$ dos alunos.

Participam obrigados a maioria não se interessa.

Muitos não se dedicam, mas esperamos novos envolvimentos.
Em processo de sustentação e aprendizagem para agir com autonomia, solidariedade e competência.

Os estudantes precisam participar das atividades principalmente nas atividades Complementares.

Participação expressiva e significativa.

Uma boa participação.

Ainda não atingimos $100 \%$, mas maioria dos estudantes tem boa participação.

Está em processo de adaptação.

Poderia ser com mais garra e motivação.

O cansaço e a pouca participação são vistos pelos professores como parte do processo de adaptação. Contudo se observamos os depoimentos dos colaboradores da pesquisa da EEEFM Carlos Drummond de Andrade que já se soma 6 anos de implantação em 2019, veremos que se faz necessário repensar estratégias de motivação. Resultando no comprometimento do envolvimento no currículo proposto pela escola. O maior envolvimento foi identificado no EEEMTI Josino Brito. (Fig. 6)
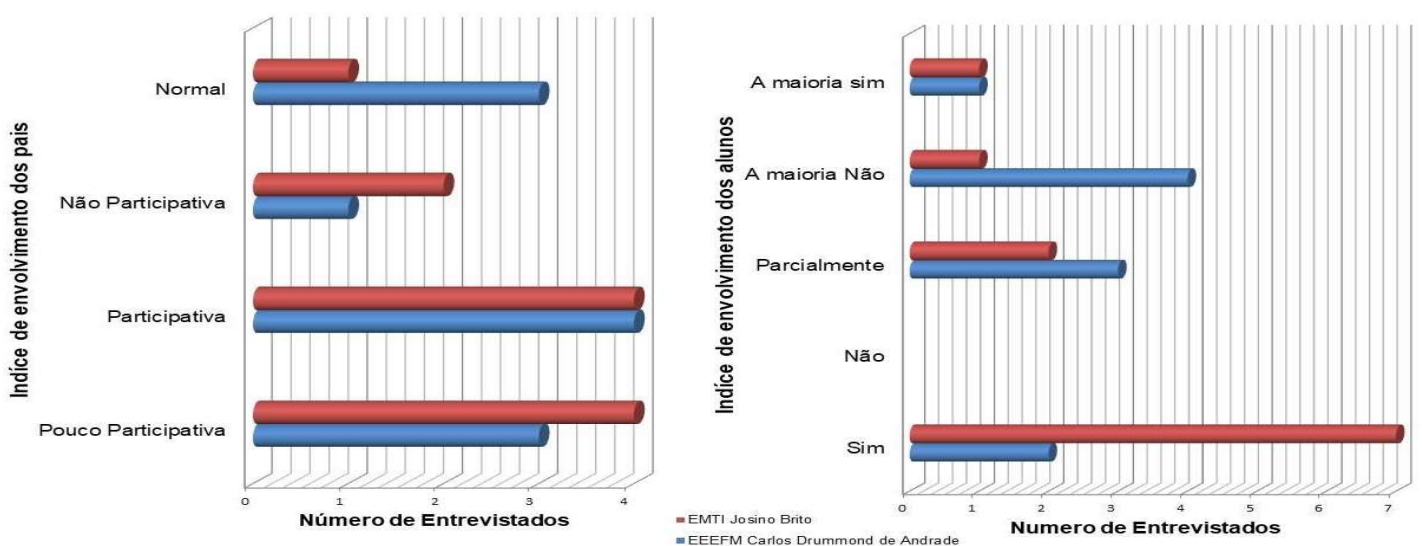

Figura 6: Percepção do docente a respeito da participação dos PAIS e/ou RESPONSÁVEIS e dos alunos na Educação Integral.

Esta foi uma interrogação aberta e foi possível identificar 4 categorias para o índice de envolvimento dos pais sendo a participativa similar nas duas escolas alcançando $36 \%$. Não recomendamos unir a categoria normal porque ela pode ter sentido distintos, por exemplo quando se pergunta a uma pessoa sobre a presença dos pais é comum ouvir que a participação é sempre pequena e que esse comportamento seria normal. A estrutura física da escola é vista como relevante para o envolvimento dos estudantes como observado no quadro 6.

Entre as justificativas para a ausência do envolvimento esperado (Quadro 6) e da possibilidade da oferta de um ensino de qualidade, para que a aprendizagem seja alcançada, está o predomínio da categoria 'infraestrutura' na EEEFM Carlos Drummond de Andrade. Já a EEEMTI Josino Brito, ainda que tenha a preocupação com a infraestrutura, ao responderem o questionário a categoria 'cuidado' ainda que oculta demonstra a preocupação dos entrevistados com o tempo a ser destinado aos alunos na ampliação da jornada escolar.

Quadro 6: Percepção sobre a estrutura e o tempo na qualidade de ensino integral.

\begin{tabular}{lll} 
: EEFM Carlos Drummond de EMTI Josino Brito \\
\hline \multirow{2}{*}{ Andrade }
\end{tabular}




\begin{tabular}{|c|c|}
\hline $\begin{array}{l}\text { A infraestrutura é fundamental para } \\
\text { aproveitar melhor o tempo. } \\
\text { Não está bom. } \\
\text { É notória a necessidade de boa } \\
\text { estrutura para atender. } \\
\text { O acolhimento. } \\
\text { A estrutura não é adequada e com } \\
\text { isso a qualidade do tempo é } \\
\text { prejudicada. } \\
\text { Falta infraestrutura. } \\
\text { Totalmente relacionada. } \\
\text { Fundamental o tempo ser bem } \\
\text { aproveitado e com conteúdo. } \\
\text { Está relacionado, pois uma depende } \\
\text { da outra. }\end{array}$ & $\begin{array}{l}\text { Para se sentirem como parte da escola, que são bem-vindos. } \\
\text { Quanto mais tempo o estudante passar na escola e melhor acolhido for, mais } \\
\text { vínculos terá e melhor será seu rendimento. } \\
\text { Baixa participação. } \\
\text { O acolhimento quanto aos estudantes faz com que eles se sintam capazes de opinar, } \\
\text { sugerir e manifestar seus anseios. Com relação a quaisquer obstáculos ou melhorias } \\
\text { para os envolvidos em sua maioria. } \\
\text { Ao tempo deles vão percebendo e assimilando. } \\
\text { Totalmente. } \\
\text { Quando são acolhidos com amor se sentem pertencidos ao ambiente e propicia a } \\
\text { aprendizagem. } \\
\text { Faz toda a diferença. } \\
\text { Quando acolhe bem, tem o melhor resultado } \\
\text { Falta estrutura. }\end{array}$ \\
\hline
\end{tabular}

\section{Concepção dos professores sobre o impacto na aprendizagem dos alunos}

Como salienta Carvalho et al. (2019) o Projeto Guaporé foi criado para diminuir a injustiça social “[...] foi instituído com o propósito de criar uma política educacional que pudesse diminuir a pobreza, por meio da ampliação do tempo de permanência do aluno na escola, mantendo a qualidade e o progresso do desempenho escolar". Objetivos que também estão inseridos na Escola do Novo Tempo/Escola da Escolha e contempla os objetivos da Meta 6 do PNE.

Se o progresso for medido por meio da aprendizagem que em grande parte se reflete em notas escolares, na opinião dos colaboradores da entrevista ainda não se alcançou o objetivo esperado na EEEFM Carlos Drummond, com $45 \%$ parcialmente e $36 \%$ sim, enquanto que para a EEEMTI Josino Brito acredita que 91\% dos estudantes apresentaram sim melhoria na qualidade de aprendizagem (Fig. 7).

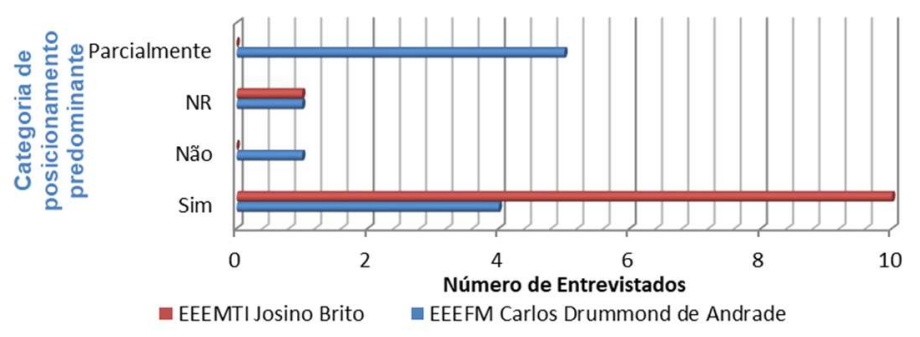

Figura 7: Percepção de melhoria na qualidade da aprendizagem do aluno.

De uma forma global ambas as experiências vêm mudando o cenário das escolas, apresentando ainda que parcialmente um avanço no processo ensino-aprendizagem. Uma das estratégias empregadas consiste na proposta de nivelamento das disciplinas das disciplinas básicas como as de língua portuguesa e de matemática. Na EEEFM Carlos Drummond 91\%, e EEEMTI Josino Brito 100\% relataram aplicar essas práxis metodológica como estratégia para diminuir a defasagem de conhecimento na série em que estão cursando. O reflexo da implantação desses projetos, é monitorado através de resultados quantitativos como índices de reprovação, aprovação desistência, notas obtidas no IDEB, ENEM entre outros instrumentos criados.

Para 64\% dos entrevistados de cada projeto, é importante para o êxito das práxis pedagógicas que, os professores proponham estratégias diversificadas considerando a especificidade de todos os estudantes e contemplando a singularidade de cada um. Em busca de ampliar o interesse e combater a ausência de 
motivação por parte dos educandos, os professores desenvolvem projetos interdisciplinares e multidisciplinares, como podemos observar em alguns relatos frente à pergunta: Você já fez alguma proposta de melhoria na qualidade do ensino e aprendizagem do aluno? Se sim, qual?

'Sim, proposta de projetos interdisciplinares para melhorar o rendimento'. (Relato 1)

'De acordo com o projeto é importante confiar nos estudantes e aguardar o tempo deles'.

'Estratégias diversificadas'. (Relato 2)

'Eu e uma colega fizemos uma pesquisa onde investigamos qual a melhor forma de aprendizagem de cada estudante e posteriormente compartilhamos com os demais professores'. (Relato 3)

'Sim, elaboração de planilhas para o professor acompanhar o rendimento / aproveitamento de estudos/aprendizagem dos estudantes'. (Relato 4)

'Sim. São propostas ambas diferenciadas na medida do possível e'. (Relato 5)

'Sim, ambos envolvente, ao grupo, fora de sala de aula, no pátio'. (Relato 6)

'Sim, projeto interdisciplinares'. (Relato 7)

'Sim, utilização da biblioteca com o quadro digital para aulas de redação'. (Relato 8)

'Sim, aqueles que trabalham um bom projeto, sempre tem um bom êxito'. (Relato 9)

(Relatos escritos pelos colaboradores da pesquisa na EEEMTI Josino Brito e EEEMTI Carlos Drummond de Andrade)

Pode-se observar nos relatos que a pedagogia do projeto é umas práxis metodológica presente em ambas as escolas. Sendo a aceitação em estudar em tempo integral uma resistência para parte dos alunos.

\section{Concepção dos professores sobre a implantação do Plano Nacional de Educação - PNE META 6 e o Plano Estadual de Educação}

Há um histórico no Brasil em que elaboração de diretrizes para educação como os Parâmetros Curriculares Nacionais e a atual Base Nacional Comum Curricular, são pensada por atores que não estão inseridas em um contexto diário escolar. Existe outro mundo entre os muros da escola que é negligenciado quando se planeja soluções para o sistema de ensino com atores exógenos a ela. Essa problemática poderia ser amenizada ou mitigada se os profissionais atuantes da educação pudessem ser consultados e sua experiência levada em consideração. As implantações das escolas em tempo integral no município de Cacoal de acordo com os relatos dos entrevistados seguiram essa tendência histórica, inicialmente pela população receber a escola e não ser consultada se teria adesão por parte deles.

É inquestionável a relevância dos dois programas, porém essas lacunas precisam ser consideradas como indicadores para reflexão. Dos entrevistados menos de $40 \%$ de ambas as escolas foram afirmativos a respeito do entendimento por toda comunidade escolar do que é educação integral. Ainda que tenha ocorrido reunião para informar sobre como seria o programa, apresentado para os pais por meio de reuniões ou audiência pública como relatado por um colaborador de pesquisa em uma ou duas reuniões.

Após a implantação dos programas surgem as respostas a essa arcaica metodologia de pensar a escola de fora para dentro. A partir da efetivação da proposta cabe aos profissionais da educação tornarem possível a proposta idealizada e mesmo diante de um árduo trabalho podemos identificar que há aceitação e refutação da ampliação da jornada escolar. Essa questão foi a que obteve maior número de colaboradores 
que optaram em não se manifestar a respeito com destaque de $45 \%$ para a EEEMF Carlos Drummond de Andrade que é pioneira na ampliação do tempo escolar no município de Cacoal.

A EEEMTI Josino Brito evidencia através da categoria 'O cansaço predomina', que está possa ser utilizada como um indicador de que a proposta curricular precisa ser repensada. Seria comum essa categoria nos primeiros seis meses a um ano do projeto, uma fase de adaptação tanto para os profissionais da educação quanto para os alunos e pais. Passando esse período a princípio haveria experiências de todos os atores do espaço escolar para repensar novas estratégias, contudo não está claro se os programas possibilitam uma real autonomia, em razão de uma agenda e uma proposta curricular própria em busca de se conquistar o sonhado 'protagonismo estudantil', uma das bandeiras também da atual BNCC.

Ainda que as diretrizes propostas pelo Plano Nacional de Educação e o Plano Estadual de Educação evidenciam o compromisso com a implantação de ensino de qualidade claramente apresentada por suas metas, pecam ao implantarem programas sem os recursos básicos necessários para alcançá-los.

Diante dessa realidade ao se posicionarem quanto à possibilidade da real efetivação da Meta 06 atendendo as recomendações da educação integral, da forma como está sendo conduzido atualmente, uma análise global dos entrevistados nos leva a concluir que $41 \%$ acreditam que é razoável a possibilidade de ser alcançada enquanto $48 \%$ parte do princípio que seja difícil. Considerando o otimismo dos profissionais que atuam nesta modalidade de ensino, se torna relevante compreender o posicionamento frente às práxis metodológica e o papel da organização pedagógica na escola no movimento que ocorre no interior das escolas para que a proposta tenha o maior índice de êxito possível.

Quadro 8: Concepção dos entrevistados a respeito à recursos financeiros, físicos, humanos e materiais, relacionado à ampliação das horas de permanência do aluno na escola.

\begin{tabular}{|c|c|c|}
\hline & EEEFM Carlos Drummond de Andrade & EMTI Josino Brito \\
\hline 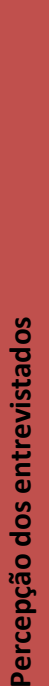 & $\begin{array}{l}\text { Recursos não são suficientes precisa de muito } \\
\text { investimento, principalmente na infraestrutura } \\
\text { da escola. } \\
\text { A demanda é muito, se tivesse apoio seria } \\
\text { melhor. } \\
\text { Outra realidade na conjuntura do ensino } \\
\text { aprendizagem. } \\
\text { É implantado e relacionado a permanência do } \\
\text { recurso no planejamento financeiro da escola. } \\
\text { Falta muito recurso para ser efetivado de forma } \\
\text { adequada. } \\
\text { De suma importância, pois comprometem o } \\
\text { resultado. } \\
\text { Ainda não se investiu o suficiente nas escolas } \\
\text { integrais. } \\
\text { Falta infraestrutura, recursos humanos e } \\
\text { materiais. } \\
\text { Insuficiente. }\end{array}$ & $\begin{array}{l}\text { Em construção, há necessidade de melhorias. } \\
\text { Mais investimento e espaço físico confortável para momento de ócio. } \\
\text { Falta uma melhor reorganização considerando o tempo de } \\
\text { aprendizagem de cada um. } \\
\text { Físicos não houve. Financeiros não sou informada sobre. Humanos são } \\
\text { qualificados, porém ainda faltam mais pessoas para ampliar o quadro e } \\
\text { não sobrecarregar ninguém. } \\
\text { Sempre procurando melhorar, mas ainda tem muita no que melhorar } \\
\text { para alguns pontos que não tem. Ex: quadra, refeitório. } \\
\text { O recurso é razoável enquanto o FUNDEB estiver colaborando. } \\
\text { Faltam recursos financeiros e estrutura física na escola. } \\
\text { Falta uma adequação do espaço físico da escola. }\end{array}$ \\
\hline
\end{tabular}

As seleções das escolas trazem duas preocupações são planejadas em duas vertentes a primeira evidenciada por Carvalho et al. (2019) “No Projeto Guaporé de Educação Integral em Rondônia, as Escolas estaduais foram escolhidas de acordo com a localização, os aspectos sociais e baixos índices de desempenho escolar", o segundo que a escola tenha uma infraestrutura básica já implantada. Neste aspecto a concepção dos entrevistados a respeito se há recursos financeiros, físicos, humanos e materiais, relacionado à ampliação 
das horas de permanência do aluno na escola, calcados na experiência evidenciam no quadro 8 quais direcionamento precisam ser feitos pelos gestores públicos para se alcançar a Meta 06.

Observa-se que a organização pedagógica é aqui evidenciada tanto no viés da supervisão pedagógica, do alinhamento da equipe e na própria organização pedagógica de suas aulas. Permeado por uma concepção didática que influenciam em como planejar e lidarem com os desafios da proposta. Predomina o percentual de entrevistados que valorizam essa prática como relevante (Quadro 9).

Quadro 9: Qual a importância organização pedagógica da escola?.

\begin{tabular}{|c|c|c|}
\hline & $\begin{array}{l}\text { EEEFM Carlos Drummond de } \\
\text { Andrade }\end{array}$ & EMTI Josino Brito \\
\hline 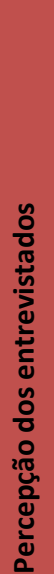 & $\begin{array}{l}\text { Grande importância pedagógica. } \\
\text { Se não estiver bem todo serão } \\
\text { penalizados } \\
\text { Elevar o nível do Conhecimento } \\
\text { Sendo a ETI uma realidade nova, } \\
\text { existe a necessidade de um } \\
\text { arcabouço de prioridades na sua } \\
\text { execução. } \\
\text { Importante para a organização } \\
\text { educacional na escola. } \\
\text { Apoio em sala, no planejamento e } \\
\text { execução. } \\
\text { Contribuir para o trabalho em equipe } \\
\text { desenvolvido na escola. } \\
\text { Grande importância pedagógica. }\end{array}$ & $\begin{array}{l}\text { Fundamental. Essa organização irá garantir o atendimento e assegurar o ensino- } \\
\text { aprendizagem dos conteúdos e desenvolver o protagonismo juvenil, as } \\
\text { competências e habilidades do jovem do século XXI. } \\
\text { Alinhamento entre a equipe escolar. Precípua. É a alma - a fazer da escola. Tudo } \\
\text { mais existe em função de ensinar a aprender. } \\
\text { Como infelizmente ainda há uma 'rotatividade" de profissionais, a organização } \\
\text { pedagógica é fundamental também para o acolhimento dos novos profissionais } \\
\text { que chegam ao projeto. É importante manter uma comunicação alinhada e manter } \\
\text { uma agenda de atividade atualizadas } \\
\text { Se ela não acontecer será impossível ao professor trabalhar seu programa de ação. } \\
\text { O professor tem horário fixo para planejamento, reunião de área, horários de } \\
\text { estudos. } \\
\text { Todos nós fazemos a intervenção na escola. }\end{array}$ \\
\hline
\end{tabular}

Da mesma forma que alguns alunos não se adapta a proposta, ocorre o mesmo com o corpo docente, o que para alguns se tornam um problema a "rotatividade de professores" o que compromete o alinhamento da equipe escolar como um todo. As mudanças também ocorrem nas diretrizes propostas para o ensino, como a atual implantação da Base Nacional Curricular, que traz mudanças a Base Curricular proposta pelo Estado e consequentemente trará alterações no Projeto Pedagógico dos estabelecimentos de ensino básico. Essas mudanças são obrigatórias e leva um tempo para que o alinhamento seja efetivado, fato que para os entrevistados também trará impacto para o planejamento educacional quanto a meta de educação integral prevista para o decênio 2014 - 2024.

\section{Motivação do docente quanto ao trabalho, com vista a Educação Integral e ampliação da jornada escolar}

Considerando que os recursos humanos são tão importantes quanto a infraestrutura e os recursos financeiros para o desenvolvimento da ampliação da jornada escolar são de suma importância identificar como cada ator inserido na instituição de ensino se sente. A valorização salarial é um dos principais objetivos da classe educacional, ao ser direcionada para quatro alternativas, considerando a análise global dos colaboradores da investigação totalizam $64 \%$ consideram o salário razoável, $5 \%$ acreditam receber um bom salário e $27 \%$ consideram o salário baixo.

Além do salário, como objetivo motivacional os profissionais que trabalham na EEEMTI Josino Brito recebem uma gratificação pela dedicação exclusiva. Porém os profissionais do EEEFM Carlos Drummond de Andrade, desde o início do projeto em 2013 tiveram a promessa e até a data da entrevista não havia sido 
implantado tal gratificação. Um outro ponto relevante é a valorização do conhecimento e do trabalho efetivado no ambiente escolar, por parte dos gestores, para $73 \%$ dos profissionais da EEEFM Carlos Drummond de Andrade e $100 \%$ da EEEMTI Josino Brito, afirmaram que o gestor educacional reconhece quando desenvolve um bom trabalho. Destes $82 \%$ dos profissionais da EEEFM Carlos Drummond de Andrade e 91\% da EEEMTI Josino Brito alegaram aceitarem sugestões para melhoria do seu trabalho quando necessário.

Considerando que a intuição de ensino básico não tem autonomia para conceder benefícios aos profissionais que atuam nela, devendo todos atenderem as responsabilidades propostas legalmente através do Regimento do Servidor Público do Estado de Rondônia. Foi solicitado aos entrevistados se gostariam de receber algum benefício, tendo como resposta mais recorrentes: 'Auxílio moradia, Auxílio saúde'; 'Dobrar a gratificação'; '20\% de gratificação que não foi comprido' e 'Plano de saúde, aumento do valor do vale alimentação'.

A estrutura organizacional (equipamentos/materiais) para desenvolverem o trabalho didático atingiu pelo menos 9\% na EEEMF e 18\% EEEMTI. 68\% afirmaram que a Escola tem Ihes oferecido oportunidades de desenvolvimento profissional. Questão referida a autonomia para desenvolverem o trabalho planejado no ambiente escolar.

\section{CONCLUSÕES}

Ainda que as duas escolas ampliem a jornada escolar, atuam práxis didática metodológica distinta: a Escola Carlos Drummond de Andrade, concentra pela manhã as disciplinas curriculares obrigatórias e pela tarde a oferta de um currículo alternativo. Já a Escola Josino Brito, trabalha com um currículo integrado sem distinção do melhor horário para as disciplinas obrigatórias, cuja as quais são mescladas com uma nova proposta curricular que inserem momentos de aprendizagem classificadas como projeto de vida, disciplinas optativas, aulas de laboratório e alinhamento entre outras.

Não é possível ainda identificar em qual delas, a proposta pedagógica está sendo mais eficiente. Porém foi visível averiguar que um programa a longo prazo que segue sem investir recursos econômico e humanos para que as metas sejam alcançadas, trazem um desconforto ao sistema de ensino que sem condições de oferecer o básico aos alunos comprometem todo o trabalho voltado a qualidade de ensino. 0 tempo na escola, é caro e pode também ser desgastante tanto para os alunos quanto para os professores que precisam manter a motivação dos alunos, para que compreendam que não se trata de um depósito de jovens e sim um espaço para que as oportunidades de aprendizagem dos discentes sejam ampliadas.

Entretanto muitos dos projetos e programas chegam à escola sem consultar a clientela, sobre qual a relevância para eles, porém ocorre de fato o comunicado que o projeto será implantado como afirmado pelos entrevistados. O mesmo ocorre com os professores, trazendo o desconforto de não fazerem parte da construção de um novo cenário escolar. Não se trata aqui de negar a relevância das propostas de ampliação da escola em tempo integral, mais de ouvir as vozes daqueles que estão inseridos nela. Ao ouvir essas vozes as políticas públicas podem se tornar mais eficazes: a rebeldia dos alunos que não querem desenvolver as 
atividades, mata aulas ou não se empenham como deveria, pode ser um indicador de que a proposta precisa ser repensada.

Não alcançar uma meta no IDEB, na Prova Brasil ou no ENEM entre outros instrumentos destinados para avaliar a dinâmica anual da qualidade de ensino, não deveria ser a grande preocupação, mas sim um outro indicador, o da necessidade de avaliarmos como as metodologias aplicadas e a forma que avaliamos esse processo reflete no objetivo traçado nas ações de cada professor. Como afirma Veiga "Se a aprendizagem é vista como resultado do processo de ensino, consequentemente, a avaliação é parte integrante desse processo" (VEIGA, 2010).

Ambas as escolas já possuem experiência suficiente para que pais, alunos, profissionais da educação e o restante da comunidade escolar possam traçar juntas metodologias para que o projeto dê certo, afinal uma educação pública de qualidade é desejo de todos, uma luta da classe trabalhadora e anos de história para que toda classe social tenha esse direito garantido (RODRIGUES, 2016). Há uma velha tradição de que tudo precisa caminhar como foi planejado, porém uma escola do novo tempo, precisa atender os anseios da sociedade e em especial dos jovens exatamente com a mentalidade da época em que está sendo inseridas. O século XXI exige um currículo flexível e professores preparados para a adaptação constante, e com o olhar sensível para que a justiça social (TORRES-SANTOMÉ, 1998) possa ocorrer através da ação coletiva do trabalho escolar.

A principal ferramenta para isso é o Projeto Pedagógico e o Regimento Escolar que precisam da inserção de todos os profissionais da educação em sua construção dos mesmos, em razão que a ausência da participação leva ao distanciamento de aplicá-lo, simplesmente por desconhecimento e não por ausência de profissionalismo. Uma proposta para que essas ferramentas sejam eficazes para o gestor público educacional seria grupos de estudos constante, e a cada funcionário novo possa integrar a análise e propor alterações diante os acontecimentos sendo na coletividade discutidos as possibilidades. Como foi identificado a rotatividade de profissionais que não se adaptam ao modelo é constante, essa seria uma alternativa.

Ao PNE propor a Escola em Tempo Integral também trouxe a necessidade de estruturá-la para que a ampliação do tempo dos estudantes na escola atenda o mínimo para garantir o bem-estar dos alunos, para que a aprendizagem dos alunos não seja comprometida. Contudo os depoimentos sobre a ausência de refeitório, espaço para descanso, juntamente com outras infraestruturas de extrema relevância como salas de laboratório bem equipadas, bibliotecas atrativas, quadras demonstra que as estratégias não estão sendo atendidas.

O Meta 6 do PNE, é claramente uma política pública socioeducacional, onde a preocupação se estende para além do pedagógico, buscando ampliar o tempo de permanência do estudante na escola, amplia também o acesso a alimentação, orientação educacional e motivações a conhecimento múltiplos elementos para uma educação para a vida. $O$ estado de Rondônia, ainda que apresenta lacuna estruturais não se pode negar que os projetos ampliaram oportunidades de se repensar novos caminhos em busca de uma educação pública de qualidade. 


\section{REFERÊNCIAS}

BARDIN, L.. Análise de conteúdo. São Paulo: Edições 70, 2011.

BRAGANÇA, I. F. S.; PEREZ, J. G. M.. Formação Continuada em Escolas de Tempo Integral: narrativas de professoras. Educ. Real., Porto Alegre, v.41, n.4, p.1161-1182, 2016. DOI: http://dx.doi.org/10.1590/2175-623660612

BRANCO, V.. Desafios para a implantação da Educação Integral: análise das experiências desenvolvidas na região sul do Brasil. Educar em Revista, Curitiba, n.45, p.111-123, 2012. DOI: http://dx.doi.org/10.1590/S0104$\underline{40602012000300008}$

BRASIL. Ministério da Educação. Portaria no 1.145, de 10 de outubro de 2016. Institui o Programa de Fomento à Implementação de Escolas em Tempo Integral, criada pela Medida Provisória no 746, de22 de setembro de 2016. Brasília: DOU, 2016.

BRASIL. Lei n.13.005, de 25 de junho de 2014. Aprova o Plano Nacional de Educação - PNE e dá outras providências. Brasília: DOU, 2014.

CARVALHO, F. R.; SANTOS, S. F.; VELANGA, C. T.. Educação integral em Rondônia: Projeto Guaporé idas e vindas de uma experiência educacional 'desastrosa'. InterMeio: revista do Programa de Pós-Graduação em Educação, Campo Grande, v.25, n.50, p.221-236, 2019.

CARVALHO, M. C. B.. O Lugar da Educação Integral na Política social. Caderno CENPEC: Educação, Cultura e Ação Comunitária, n.2, p.07-13, 2006.
ESTÊVÃO, C. V.. Justiça social e modelos de educação: para uma escola justa e de qualidade. Rev. Diálogo Educ., Curitiba, v.16, n.47, p.37-58, 2016. DOI: http://doi.org/10.7213/dialogo.educ.16. 047.DS02

PEREIRA, I. A.. Gestão escolar e seus modelos: um desafio para a qualidade de ensino. Educationis, v.8, n.1, p.23-36, 2020. DOI: http://doi.org/10.6008/CBPC23183047.2020.001.0003

PRODANOV, C. C.; FREITAS, E. C.. Metodologia do trabalho científico: métodos e técnicas da pesquisa e do trabalho acadêmico. 2 ed. Rio de Janeiro: Feevale, 2013.

REIS, C.; CARAMELLO, N.. Escola do Novo Tempo em Rondônia: modelo educacional que possibilitou inserir o diálogo polar como disciplina eletiva. In: Educação ambiental: ensino, pesquisa e práticas aplicadas. Ituiutaba: Barlavento, 2017. p.965-977.

SILVEIRA, D. T.; CÓRDOVA, F. P.. A pesquisa Científica. In: GERHARDT, T. E.; SILVEIRA, D. T.. Métodos de pesquisa. Porto Alegre: UFRGS, 2009. p.120.

TORRES-SANTOMÉ, J.. Globalização e Interdisciplinaridade: o currículo integrado. Porto Alegre: Artes Médicas, 1998.

VEIGA, I. P. A.. Projeto político pedagógico da escola: uma construção possível. 29 ed. Campinas: Papirus, 2013.

A CBPC - Companhia Brasileira de Produção Científica (CNPJ: 11.221.422/0001-03) detém os direitos materiais desta publicação. Os direitos referem-se à publicação do trabalho em qualquer parte do mundo, incluindo os direitos às renovações, expansões e disseminações da contribuição, bem como outros direitos subsidiários. Todos os trabalhos publicados eletronicamente poderão posteriormente ser publicados em coletâneas impressas sob coordenação da Sustenere Publishing, da Companhia Brasileira de Produção Científica e seus parceiros autorizados. Os (as) autores (as) preservam os direitos autorais, mas não têm permissão para a publicação da contribuição em outro meio, impresso ou digital, em português ou em tradução. 